\title{
Research on the Current Situation and Strategy of E-commerce Development of Chinese Medicinal Materials in Gansu Province
}

\author{
Jing $\mathrm{Xu}^{1}$ and Peilei $\mathrm{Wu}^{1}$ \\ ${ }^{1}$ School of Economics, Northwest Minzu University, Lanzhou, Gansu, China
}

\begin{abstract}
At present, there are some problems in e-commerce of Chinese medicinal materials in Gansu Province, such as insufficient awareness of the development of business entities, loss of regional brand advantages, great differences in the quality of Chinese medicinal material commodities, and empty trading platform. This paper proposes to strengthen the brand building, establish a unified standard, pay attention to personnel training, speed up the construction of network platform and the Chinese medicine logistics system.
\end{abstract}

Acknowledgement. This article is supported by the national information e-commerce key laboratory of Gansu province's higher education institutions. Also, it is the result of the opening phase of the laboratory of Northwest University for Nationalities (Project Approval No: SYSKF - 2018095).

Gansu province is a large province of traditional Chinese medicinal materials planting. It has been recorded in historic data that Gansu province has a history of planting Chinese medicinal materials for thousands of years. In recent years, the development momentum of traditional Chinese medicines in Gansu Province has continued to leap forward. In 2014, the planting area of Chinese medicinal materials in Gansu Province was 3.837 million mu, and the output was 983 thousand tons. In 2016, the planting area reached 4.05 million $\mathrm{mu}$, and the output was 1.1 million tons, continues to maintain the first place in the country, the market influential force has been significantly enhanced. It has become one of the pillar industries in Gansu province. Due to the limited attributes of special agricultural products of Chinese medicinal materials and the lack of relevant information, the development of e-commerce of Chinese medicinal materials in Gansu Province has been seriously restricted.

\section{Related concepts}

The Organization for Economic Co-operating and Development (OECD) believes that e-commerce is a business activity between enterprises and enterprises, enterprises and consumers on an open network, including intranets, extranets and Internet. Chinese medicinal materials are unprocessed or simply processed medicines from natural sources, commonly known as "medicinal materials", usually divided into botanical drugs, animal drugs and mineral drugs. Chinese medicinal materials can be processed into pieces for clinical use, or also as raw materials. E-commerce of Chinese medicinal material is a series of electronic trading activities about the production, supply and sale of Chinese medicinal materials.

\section{Research status at home and abroad}

Foreign scholars have carried out research in many fields and perspectives, such as guiding the transformation of traditional enterprises, agricultural e-commerce means (Agric-EC), e-commerce retail expansion, e-commerce revision framework, e-commerce agriculture poverty alleviation, building virtual communities, improving the efficiency of agricultural products circulation, and intelligent e-commerce of agricultural products, not involving China's unique Chinese medicinal materials e-commerce .Domestic scholars in the field of agricultural products e-commerce mainly analyzed from aspects of the agricultural products network marketing model, agricultural products e-commerce model, agricultural products logistics model, agricultural products or agricultural products of local characteristics e-commerce development status etc. In terms of Chinese medicinal materials, Gansu Province has formed ten famous brands of Gansu medicines, which have a number of good products and have certain influence in the country. However, single products with annual sales of over 100 million are very few, lacking market influence and competitiveness. The establishment of superior brands of Chinese medicinal materials is not symmetrical with the development of Chinese medicinal materials industry. There are very few studies on e-commerce of Chinese medicinal materials. This paper takes the electronic commerce of Chinese medicinal materials in Gansu 
Province as the research object, using the network platform to search the sales data of Chinese medicinal materials stores of Gansu province on Taobao and Tmall.

\section{Development status and problems of Chinese medicinal materials e-commerce in Gansu province}

\subsection{The awareness of business entities development is insufficient and there is lack of brand awareness}

In Chinese medicinal materials e-commercial entities, there are wholesalers, agricultural cooperative organizations, production and marketing integration organizations with relatively strong financial strength, as well as relatively weak and decentralized farmers, farms and individual vendors. When small-scale entities participate in the market competition or trading, they do not have a comprehensive grasp of information, lack the ability to respond to the market, and are at a disadvantage position in the trading process. Those enterprises which began to take the shape mostly have strong economic strength, have a good grasp of market information, can make better economic decisions, and have a strong ability to control and respond to the market. It is easy for large-scale e-commerce entities to form an interest alliance to monopolize the market, so that the interests of small and medium-sized e-commerce of Chinese medicinal materials are squeezed, there are problems with goods available but no one to buy.

Up to August 6th, 2018, a total of 7575 online stores of Chinese medicinal materials in Gansu Province were searched on the home page of Taobao, including 7339 stores on Taobao platform and 236 stores on Tmall platform. If the location of e-commerce registration is in Gansu Province, the number of stores on Taobao is reduced to 200, and stores on Tmall are only 7 . The main products of these stores are Angelica sinensis, Codonopsis pilosula and Radix Astragali, forming an e-commerce with Dingxi and Min county in Gansu Province as the main producing areas. The specific sales situation is shown in Table 1 and table 2.

Table 1. Sales of top 15 Chinese medicinal materials Taobao and Tmall shops in Gansu province.

\begin{tabular}{|c|c|c|c|}
\hline Shop name & $\begin{array}{c}\text { Sales } \\
\text { volume } \\
\text { (piece) } \\
\text { month }\end{array}$ & $\begin{array}{c}\text { Belonged } \\
\text { to } \\
\text { platform }\end{array}$ & $\begin{array}{c}\text { Registered } \\
\text { address of } \\
\text { shop }\end{array}$ \\
\hline $\begin{array}{c}\text { Minfu food } \\
\text { monopolized store }\end{array}$ & 70540 & Tmall & Lanzhou \\
\hline Juhetai flagship store & 18891 & Tmall & Dingxi \\
\hline $\begin{array}{c}\text { Original green farm } \\
\text { store }\end{array}$ & 2779 & Taobao & Dingxi \\
\hline $\begin{array}{c}\text { Mingyang Chinese } \\
\text { medicinal material } \\
\text { health preservation } \\
\text { Hall }\end{array}$ & 2260 & Taobao & Dingxi \\
\hline $\begin{array}{c}\text { Silk Road food } \\
\text { monopolized store }\end{array}$ & 2136 & Tmall & Dingxi \\
\hline
\end{tabular}

\begin{tabular}{|c|c|c|c|}
\hline $\begin{array}{c}\text { Ling Ling's farm } \\
\text { store }\end{array}$ & 1531 & Taobao & Dingxi \\
\hline $\begin{array}{c}\text { Minxian County } \\
\text { Angelica sinensis } \\
\text { family }\end{array}$ & 1136 & Taobao & Dingxi \\
\hline $\begin{array}{c}\text { Guanqu special } \\
\text { product }\end{array}$ & 935 & Taobao & Lanzhou \\
\hline $\begin{array}{c}\text { Dameitianshui } \\
\text { QingcaotangChinese } \\
\text { medicinal materials }\end{array}$ & 777 & Taobao & Dingxi \\
\hline $\begin{array}{c}\text { Cuishengtang Food } \\
\text { Baixinyuan Food }\end{array}$ & 753 & Taobao & Lanzhou \\
\hline Guixiangti & 538 & Taobao & Dingxi \\
\hline $\begin{array}{c}\text { Xibuyuansheng } \\
\text { special product }\end{array}$ & 522 & Taobao & Dingxi \\
\hline $\begin{array}{c}\text { Miss Huangtunv } \\
\text { special product }\end{array}$ & 509 & Taobao & Qingyang \\
\hline
\end{tabular}

Table 2. Sales of top 5 Chinese medicinal materials Taobao and Tmall stores in China.

\begin{tabular}{|c|c|c|c|}
\hline Shop name & $\begin{array}{c}\text { Sales } \\
\text { volume } \\
\text { (piece)/ } \\
\text { month }\end{array}$ & $\begin{array}{c}\text { Belonged } \\
\text { to } \\
\text { platform }\end{array}$ & $\begin{array}{c}\text { Registered address } \\
\text { of shop }\end{array}$ \\
\hline $\begin{array}{c}\text { Minfu food } \\
\text { monopolized } \\
\text { store }\end{array}$ & 70540 & Tmall & Lanzhou \\
\hline $\begin{array}{c}\text { Thousand petals } \\
\text { renamed Jia } \\
\text { food ingredients }\end{array}$ & 62675 & Taobao & Shanghai \\
\hline $\begin{array}{c}\text { ShanyifangFlags } \\
\text { hip store }\end{array}$ & 58654 & Tmall & Yinchuan, Ningxia \\
\hline $\begin{array}{c}\text { Chimamaxiang } \\
\text { sauce shop }\end{array}$ & 48941 & Taobao & Shanghai Pudong \\
\hline $\begin{array}{c}\text { Liaoweiyuan } \\
\text { spices }\end{array}$ & 36348 & Taobao & Weifang, Shandong \\
\hline
\end{tabular}

Table 1 shows that the top 15 sales of Taobao Tmall of Gansu-based Chinese medicinal materials e-commerce. There is a big gap of sales volume between the first Tianmao store Minfu food monopolized store and the second Juhetai flagship store. Table 2 shows that the top 5 sales of Taobao Tmall of Chinese medicinal materials e-commerce, Minfu food monopolized store still ranks first, Juhetai flagship store ranks 12. Other top rankings are mostly foreign shops such as Ningxia, Bozhou, Anhui Province, indicating that Minfu food monopolized store has formed a certain brand advantage, while other stores in Gansu have not yet formed shop brand advantage. "Gansu Province Chinese medicinal materials " has formed a regional brand advantage, but the essence of this advantage is mainly occupied by the e-commerce of other areas.

\subsection{The quality of commodities is uneven}

There are not only scaled Chinese medicinal materials manufacturers in Gansu province, but also small 
self-management households on Taobao and WeChat, Chinese medicinal materials e-commerce is facing the problem of quality control, specifically manifested in: product quality differences, product preservation in the process of transportation, differences of warehousing cost and means, making the quality of Chinese medicinal materials products uneven and lack protection.

In addition, Chinese medicinal materials products have a certain particularity, e-commerce platform can not meet the requirements of on-site inspection of transactions. The definition of "Chinese medicinal materials" and "agricultural and sideline products" is not clear enough in the circulation process of Chinese medicinal materials market in china. The standards of Chinese medicinal materials are various, which leads to some businessmen exploring advantages in the circulation of products. Some expired, deteriorated, subprime or even counterfeit Chinese medicinal materials are mixed in the market, restricting the development of Chinese medicinal materials and their e-commerce.

\subsection{It lacks e-commerce talents}

Gansu Province is located in the western backward area, compared with the eastern developed provinces and cities there is a great gap between their network facilities and information construction. Coupled with the late start of e-commerce of Chinese medicinal materials in Gansu Province, the main business entities are ordinary farmers. They have poor ability to accept e-information and most of them do not have e-commerce operation ability. It is difficult to establish a network brand and implement network marketing promotion activities.

\subsection{The trading platform construction is imperfect}

At present, besides enterprise-built websites and farmers selling products through the third-party network platform, Gansu Province has also established a number of electronic information network trading platforms to provide services for Chinese medicinal materials trading and issued information of planting, processing and market trading. For example, Chinese medicinal materials world. com and Gansu Trading Center of Chinese medicinal materials etc., However, these trading platforms are generally lack of professional management and maintenance, can not release information timely, don't introduce product in details and online customer service perform practically no functions, so that the transaction concluded through the web page is almost zero.

In addition, Gansu lacks professional Chinese medicinal materials information network construction. During the purchase season of Chinese medicinal materials, the circulation channels of Chinese medicinal materials will increase and become extremely unstable. The drug dealers often intend to depress the prices of products at the time of purchase, which damages the interests of many parties. Although the State Administration of Medicine has set up information centers for Chinese medicinal materials, the information networks have been set up in various places, and more than ten websites related to Chinese medicinal materials have been set up in Gansu Province, it is difficult to estimate planting areas and yields because of the complicated market situation of Chinese medicinal materials and the scattered storage by farmers. Moreover, the cycle of information collection, collation, publication and dissemination of various media takes a long time. The undulatory property of transactions is big, information feedback lags behind production decisions, making farmers easy to make wrong production decisions.

\subsection{The construction of supporting logistics system is not perfect}

Currently, the logistics industry of Chinese medicinal materials in Gansu is still in the initial stage of development. As a special agricultural product, the logistics of Chinese medicinal materials still belongs to the logistics of agricultural products in nature. The transportation and distribution of Chinese medicinal materials are managed separately by traditional transportation and highway departments etc.. The production, processing, packaging and storage of Chinese medicinal materials are supervised by quality supervision department, drug supervision department and quarantine department. Under such multi management mode, it is very difficult to form an integrated planning and management coordination of Chinese medicinal materials logistics.

\section{Countermeasures and suggestions}

\subsection{We should strengthen brand building and attach importance to leading enterprises}

First of all, we should actively develop representative local brands in Gansu Province, strive to strengthen the cultivation of brand awareness of farmers and enterprises, and promote the brand through television, radio, WeChat, QQ and other medias, publicize brand advantages, highlight brand characteristics, enhance the competitiveness of Chinese medicinal materials, shape good images of the products and e-commerce of Chinese medicinal materials in Gansu Province.

Secondly, we should attach importance to the construction of leading enterprises and agricultural cooperative organizations, change the traditional family management and planting methods of Chinese medicinal materials, vigorously promote the construction of planting bases and production bases, further improve the quality of Chinese medicinal materials and achieve large-scale and standardized production. Leading enterprises, as a bridge connecting farmers and markets, are conducive to increasing farmers' income, realizing the application and popularization of new technologies and promoting the standardized and cluster management of industries, so that to reduce the differences of Chinese medicinal materials e-commerce. 


\subsection{We should establish unified standards and ensure product quality}

It is necessary to establish a unified standard for e-commerce of Chinese medicinal materials as soon as possible so as to solve the problem that the quality of e-commerce products of Chinese medicinal materials is difficult to control. The unified standard should include the operation standard and the quality standard of Chinese medicinal materials. The "E-commerce Standard for Chinese Medicinal Materials" issued in 2015 fills the blank in the industry, but it involves few varieties of Chinese medicinal materials and needs to be further improved.

\subsection{We should pay attention to the training of e-commerce talents}

The development of e-commerce is inseparable from the professional talents of e-commerce. The government of Gansu Province should introduce policies for the introduction and support of e-commerce talents, such as providing relevant policies to encourage relevant enterprises, colleges and research institutes in Gansu Province to introduce e-commerce talents and provide fund subsidies to colleges and research institutes which develop e-commerce talents training and e-commerce related personnel training. Through dual channels of the introduction and internal training to provide a sustainable talent reserve for the development of e-commerce in various industries of Gansu Province.

\subsection{We should speed up the construction of network trading platform}

The construction of network information platform and trading platform is the only way for the development of e-commerce. It should be led by the government to entrust relevant universities or research institutes to establish a special platform for electronic commerce information service and trading of Chinese medicinal materials. On the one hand, the platform can provide dynamic market information and logistics service information for the relevant parties in the Chinese medicinal materials e-commerce supply chain, reduce the information asymmetry in the process of Chinese medicinal material production and sales, and enhance the accuracy and pertinence of the management decisions of all parties. On the other hand, the government of Gansu Province should not only publicize and promote the E-commerce information service and trading platform of Chinese medicinal materials by itself, but also encourage the E-commerce of Chinese medicinal materials in Gansu Province to enter into the platform, which should be promoted by these E-commerce companies, and constantly broaden the network operation channels. This requires the government to guide and encourage, and provide financial and technical support, so that the network trading platform can not only be built, but also more sustainable operated, healthy developed.

\subsection{We should speed up the construction of Chinese medicinal materials logistics system}

We should improve the cooperation ability of the participants in the supply chain of Chinese medicinal materials and solve the main problems of scattered, small and disorderly logistics bodies by combining logistics policies. The government should optimize the logistics policy of Chinese medicinal materials, according to the overall requirements of modern e-commerce on logistics and the actual situation of Gansu Province, put forward the overall thinking, objectives, strategic layout and overall guidance policy of the development of Chinese medicinal materials logistics, reduce the problem of conflicting authority among departments and inefficient implementation. At the same time, the government should strengthen the policy support for the construction of the logistics system of Chinese medicinal materials, and improve the logistics infrastructure of Chinese medicinal materials in Gansu Province.

\section{References}

1. Ma Shihua Supply chain management [M]. Wuhan: Huazhong University of Science and Technology press, 2010: 189.

2. Efrem, E-business (Seventh Edition) [M]. Translated by Shi Qiliang. Machinery Industry Press, 2014

3. O. Folorunso, Sushil K. Sharma, H.O.D Longe, K. Lasaki, An Agent-based Model for Agriculture E-commerce System [J]. Information Technology Journal, 2006, vol.5 (2), pp.230.

4. I. Kotliarov, Tools to Provide Farmers with Market Access [J]. Problems of Economic Transition, 2014, vol.57 (4), pp.70-89.

5. S Chen, J Ning. Constraints on E-commerce in Less Developed Countries: The Case of China [J]. Stephen Chen, Jian Ning. Electronic Commerce Research. 2002 (1).

6. Bamiduro, J. A.; Gbadeyan, Small Scale Farming and Agricultural Products Marketing for Sustainable Poverty Alleviation in Nigeria [J]. Canadian Social Science, 2011, vol.7, Issue 3, p.125.

7. G Lin, H Zhongwei. Analysis of agricultural products E-commerce models based on supply chain management $[\mathrm{J}]$. International Conference on E-business \& E-government, 2011: 1-3.

8. WENW. A knowledge-based intelligent electronic commerce system for selling agricultural products [J]. Computers and Electronic in Agriculture, 2007, 57: 33-46.

9. Lian Wei. Research on network marketing mode of agricultural products in China [D]. Heilongjiang: Harbin University of Science and Technology, 2010-03-01.

10. Wang Chongjin. Research on the mode of China's agricultural electronic commerce [D]. Hubei: Huazhong Normal University, 2013.

11. Huang Yuhong. Research on China's Agricultural Products Logistics Model under Electronic Commerce $[\mathrm{J}]$. Journal of Harbin Commercial 
University: Social Science Edition, 2006 (2): 25-27.

12. Gu Wen, Huang Liping. E-commerce for agricultural products is ready for [J]. E-commerce, 2005 (4): 69 71.

13. Peng Jian. Challenges and Countermeasures for Developing E-commerce of Agricultural Products in Hunan Province $[\mathrm{J}]$. Anhui Agricultural Science, 2007, 35 (3): 934-935, 938. 